\title{
Pattern Recognition of Human Face With Photos Using KNN Algorithm
}

\author{
Dedy Kurniadi ${ }^{1}$, Andre Sugiyono ${ }^{2}$, Linggar Alfithna Wardaya ${ }^{3}$ \\ ${ }^{1}$ Universitas Islam Sultan Agung \\ Jl. Raya Kaligawe km.4, e-mail: ddy.kurniadi@unissula.ac.id \\ ${ }^{2}$ Universitas Islam Sultan Agung \\ Jl. Raya Kaligawe km.4, e-mail: andre@unissula.ac.id \\ ${ }^{3}$ Universitas Islam Sultan Agung \\ JI. Raya Kaligawe km.4, e-mail: linggar@unissula.ac.id
}

\section{ARTICLE INFO}

Article history:

Received 23 June 2021

Received in revised form 20 July 2021

Accepted 26 July 2021

Available online 31 July 2021

\begin{abstract}
A Facial photos in today's era are widely used as a media for identity recognition, but not many computer applications provide identity recognition of face photos that contain the names of the photo owners, to make an a prototype the sistems use a KNN algorithm, this algorithm work is by classifying the closest object and grouping it on predetermined objects. In this paper, the object is a face photo where the KNN algorithm will be used to classify the facial patterns contained in the photo. The stages in pattern recognition, starting from preprocessing, feature extraction and then classification. In addition to using the KNN algorithm for data classification, photo of faces will be detected and stored the T-Zone area and frontal face. In this paper 11 images used for data testing and the accuracy will be calculated using a recognition algorithm. The results of this paper are a facial recognition program using python that can display faces with a validity level of $82 \%$.
\end{abstract}

Keywords: pattern recognition, KNN Algorithm

\section{Introduction}

Foto adalah citra yang didapatkan dari kamera, baik itu kamera dslr, kamera smartphone ataupun kamera cctv yang mempunyai fungsi merekam object pada waktu-waktu dan kejadian tertentu. Tentu saja gambar yang berada pada foto berbagai macam, mulai dari pemandangan alam hingga gambar wajah manusia [1], [2]. Objek pada foto tersebut akan dikenali oleh manusia apabila terdapat pola yang sudah umum manusia lihat. Pattern recognition atau sering disebut pengenalan pola adalah teknik dibidang pembelajaran mesin (machine learning), pada penelitian ini difokuskan pada proses klasifikasi objek ke dalam kelas - kelas tertentu untuk mengelompokkan data sesuai dengan kelasnya. Pattern recognition digunakan untuk mengetahui atau mengindentifikasi objek dari sebuah media yang pada penelitian ini menggunakan media foto [3]. Foto wajah bisa diambil polanya untuk dikenali dan digunakan sebagai pengenalan identitas.

Sebelum pola wajah dapat dikenali, foto akan terlebih dahulu melewati beberapa proses. Pertama preprocessing yaitu tahap pemrosesan data agar data yang dihasilkan dapat sesuai dengan 
kebutuhan ekstraksi fitur. Pada tahap ini foto yang telah diambil akan diubah menjadi skala keabuan (grayscalling). Tahap selanjutnya yaitu ekstraksi fitur. Pada proses ekstraksi fitur foto yang telah diubah menjadi skala keabuan akan diubah lagi menjadi angka - angka koordinat yang kemudian akan dilanjutkan ke tahap selanjutnya yaitu pengklasifikasian [4].

Algoritma yang digunakan dalam penelitian ini adalah algoritma KNN (K-Nearest Neighbor) dengan menggunakan jarak tetangga yang berdekatan. Pada penelitian ini foto wajah akan diproses kemudian diambil koordinatnya menggunakan T-Zone area dan Frontal face kemudian jarak koordinat dihitung dengan menggunakan algoritma KNN.

\section{Research Method}

\subsection{Algoritma KNN}

Algoritma KNN (K-Nearest Neighbor) merupakan teknik atau metode untuk melakukan klasifikasi terhadap object melalui data training dengan menggunakan jarak yaitu jaraknya paling dekat dengan objek tersebut [5], [6]. KNN merupakan metode yang bersifat supervised dimana hasil dari query instance yang baru diklasifikasikan berdasarkan mayoritas kategori pada KNN. KNN digunakan pada fase klasifikasi dimana fitur - fitur yang telah melalui tahap sebelumnya. Kemudian fitur yang sama tersebut selanjutnya akan dihitung sebagai testing data. Dari perhitungan akan menghasilkan jarak, kemudian jarak dari vector yang baru ini akan dihitung terhadap seluruh vector sampel yang ada kemudian akan diambil k yang terdekat [7]. Dengan ini titik yang baru tersebut akan dapat diprediksi termasuk klasifikasi terbanyak dari titik - titik tersebut.

KNN digunakan pada fase klasifikasi dimana fitur - fitur yang telah melalui tahap sebelumnya. Fitur - fitur yang sama kemudian akan dihitung untuk testing data. Jarak dari vector yang baru ini akan dihitung terhadap seluruh vector sampel yang ada kemudian akan diambil $\mathrm{k}$ yang terdekat [8]. Dengan ini titik yang baru tersebut akan dapat diprediksi termasuk klasifikasi terbanyak dari titik - titik tersebut .

Untuk mengklasifikasikan jarak antara data training dan data testing dapat menggunakan rumus Euclidean Distance sebagai berikut.

$$
\begin{aligned}
& =\sqrt{\left(q_{1}-p_{1}\right)^{2}+\left(q_{2}-p_{2}\right)^{2}+\ldots+\left(q_{n}-p_{n}\right)^{2}} \\
& =\sqrt{\sum_{i=1}^{n}\left(q_{i}-p_{i}\right)^{2}}
\end{aligned}
$$

Dimana :

$$
\begin{aligned}
& \mathrm{N}=\text { Jumlah Dimensi } \\
& \mathrm{Q}=\text { Data Training } \\
& \mathrm{P}=\text { Data Testing }
\end{aligned}
$$

\subsection{Teknik Pengelanan Pola}

\subsubsection{Preprocessing}

Preprocessing yaitu tahapan setelah citra diubah menjadi citra digital. Pada tahap preprocessing berperan penting dalam pengolahan data. Proses ini bertujuan untuk meningkatkan kualitas citra yang akan digunakan sesuai dengan kebutuhan penelitian. Adapun tahapan dalam preprocessing [9].

Sebelum data diolah menjadi data yang dibutuhkan, data harus melewati berbagai proses terlebih dahulu. Mulai dari akuisisi citra, preprocessing hingga pada tahap akhir yaitu evaluasi. Akuisisi citra yaitu perubahan citra analog menjadi citra digital.

\subsubsection{Ekstrasksi Fitur}

Ekstraksi fitur merupakan tahapan slanjutnya ketika citra yang dihasilkan pada tahap preprocessing sudah sesuai. Ekstraksi fitur merupakan bagian penting dalam analisis TRANSFORMATIKA Vol. 19, No. 1, July 2021: 17-25 
citra. Pada tahap ini bertujuan untuk memperoleh informasi dari masing - masing citra yang kemudian akan diolah [10].

Ekstraksi fitur pada citra merupakan tahapan penting dalam pemrosesan citra digital. Karena pada ekstraksi fitur diharapkan bisa menghasilkan fittur yang sempurna yang bisa menggambarkan konten pada citra. Ekstraksi fitur sendiri yaitu mengambil nilai - nilai unik serta informasi yang berguna dari setiap citra. Fitur - fitur pada citra juga sering disebut sebagai signature of image atau tandatangan dari sebuah citra. Ada beberapa fitur yang bisa diekstrak dari suatu citra, yaitu warna, tekstur dan bentuk. Ketiga fitur tersebut sering disebut sebagai low level features.

Pada ekstraksi fitur ini menggunakan library yang berada pada software python. Library yang digunakan yaitu library T-Zone yang bertujuan untuk ekstraksi fitur mata, hidung dan mulut pada wajah, library face recognition yang bertujuan untuk mendapatkan fitur garis pada wajah sehingga akan mendapatkan pola wajah pada citra dan library frontal face yang bertujuan untuk mendapatkan keseluruhan pengenalan pola wajah mulai dari bagian T-zone (mata, hidung dan mulut) dan bagian tepi wajah.

\subsubsection{Klasifikasi}

Pada tahap klasifikasi, data yang telah diolah pada tahap selanjutnya akan dikelompokkan dengan memberi label pada citra yang telah diidentifikasi. Klasifikasi pada penelitian ini menggunakan metode K-Nearest Neighbor. Pada tahap sebelumnya yaitu preprocessing didapatkan hasil berupa titik koordinat pada data citra testing, kemudian pada tahap klasifikasi koordinat tersebut akan dikelompokkan berdasarkan jarak terdekatnya dari data citra training [11].

\subsubsection{Akurasi}

Setelah semua tahap dilewati, proses selanjutnya yaitu menghitung akurasi atau ketepatan pada sistem. Akurasi ini bertujuan untuk menilai seberapa tepatkah metode KNN yang diterapkan pada sistem. Akurasi ini menggunakan rumus.

$$
\text { Akurasi }=\frac{\text { jumlah prediksi benar }}{\text { jumlah total prediksi }} \times 100 \%
$$

Jumlah prediksi benar adalah hasil dari data testing yang mempunyai kelas dan label sama dengan data training yang ada pada sistem dan jumlah total prediksi merupakan jumlah dari keseluruhan data testing .

\section{Results and Analysis}

\subsection{Pengumpulan Data}

Proses pengumpulan data citra pada penelitian ini menggunakan citra wajah dosen pada Fakultas Teknologi Industri (FTI) Universitas Islam Sultan Agung (Unissula) Semarang. Data pada penelitian yang digunakan adalah 9 citra digunakan sebagai data training dan 5 citra dimana terdapat 11 wajah yang akan dikenali digunakan sebagai data testing. Pada tabel 3.1 merupakan daftar data citra wajah yang digunakan sebagai data training.

Tabel 3.1 Data Training

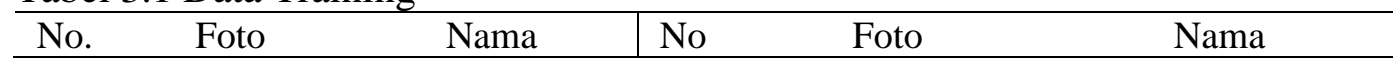




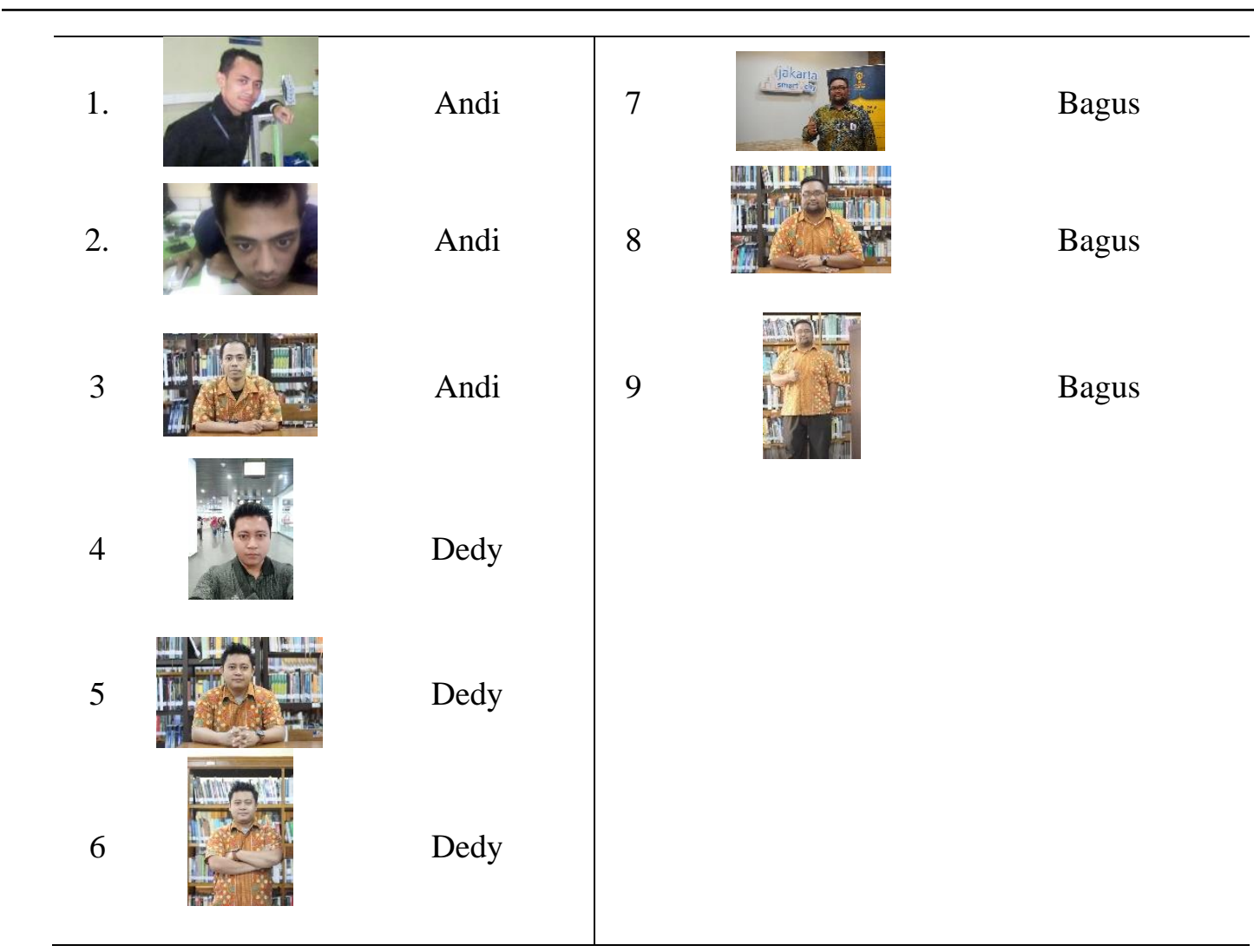

Dari tabel data training tersebut kemudian akan ditesting dengan algoritma KNN, Hasil dari tesing ditunjukkan pada tabel 3.2

Tabel 3.2 Proses cropping

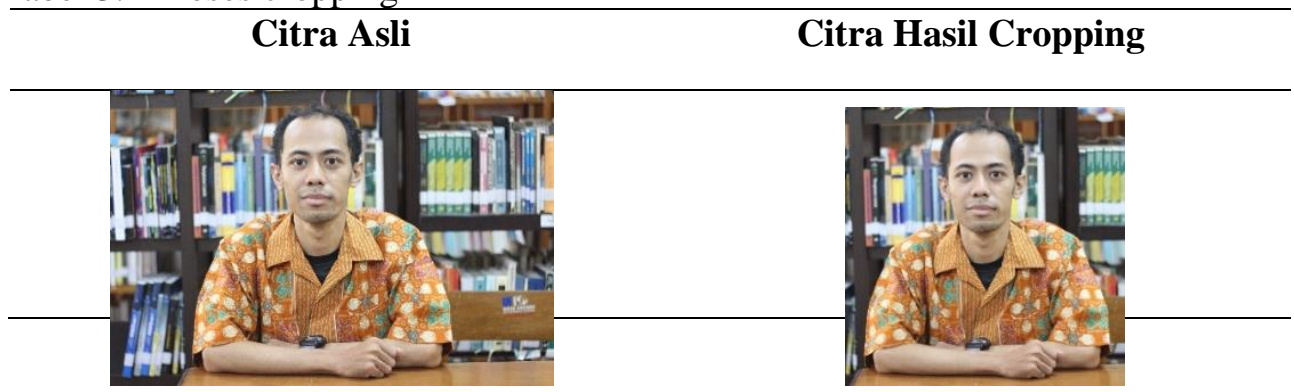

setelah citra diubah menjadi persegi, citra akan diubah menjadi citra dengan resolusi 256 x 256 piksel, sehingga semua citra data akan mempunyai resolusi yang sama.

Tabel 3.3 Proses resizing

Citra Asli Citra Setelah Resize

TRANSFORMATIKA Vol. 19, No. 1, July 2021: 1 7-25 


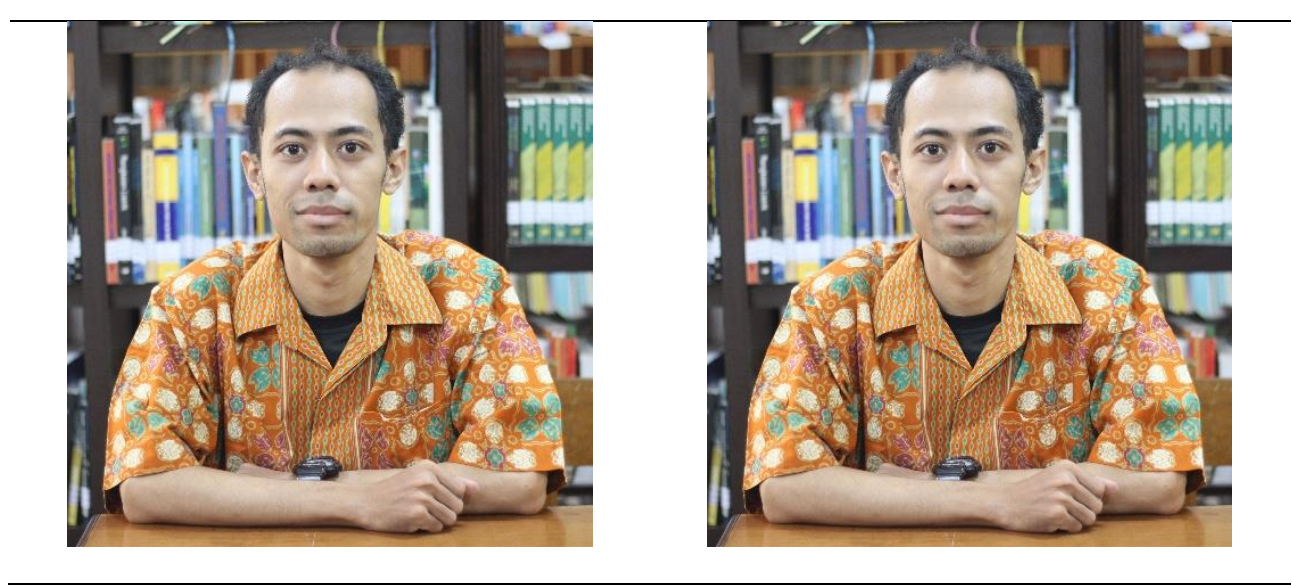

Selanjutnya Proses merubah citra berwarna menjadi citra grayscale dilakukan dengan tujuan untuk mengubah nilai (Red, Green, Blue) dalam satu piksel citra menjadi hanya mempunyai satu nilai dalam satu piksel citra.

Tabel 3.4 Proses grayscalling

\section{Citra Asli Citra Setelah Grayscalling}
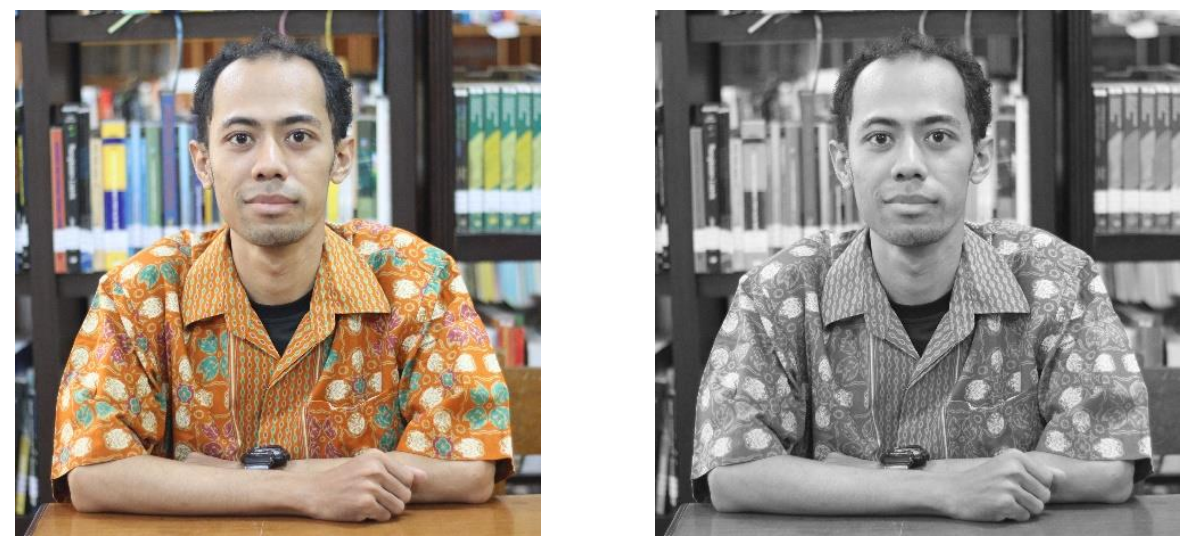

Tabel 3.5 Hasil testing

\begin{tabular}{|c|c|c|c|c|}
\hline \multirow{2}{*}{ No. } & \multirow{2}{*}{ Hasil Pengenalan Wajah } & \multicolumn{2}{|c|}{ Koordinat } & \multirow{2}{*}{ Keterangan } \\
\hline & & {$[\mathrm{X}]$} & {$[\mathrm{Y}]$} & \\
\hline \multirow[t]{2}{*}{1.} & Data Testing 1 & & & \\
\hline & - Andi & 339 & 494 & Wajah 1 \\
\hline \multirow[t]{5}{*}{2.} & Data Testing 2 & & & \\
\hline & - unknown & 128 & 336 & Wajah 2 \\
\hline & - $\quad$ Andi & 504 & 297 & Wajah 3 \\
\hline & - Dedy & 335 & 260 & Wajah 4 \\
\hline & - $\quad$ Bagus & 674 & 225 & Wajah 5 \\
\hline \multirow[t]{2}{*}{3.} & Data Testing 3 & & & \\
\hline & - Dedy & 199 & 104 & Wajah 6 \\
\hline
\end{tabular}




\begin{tabular}{|c|c|c|c|c|}
\hline \multirow{3}{*}{4.} & - $\quad$ Dedy & 494 & 136 & Wajah 7 \\
\hline & Data Testing 4 & & & \\
\hline & - Bagus & 648 & 202 & Wajah 8 \\
\hline \multirow[t]{4}{*}{5.} & Data Testing 5 & & & \\
\hline & - $\quad$ Dedy & 103 & 140 & Wajah 9 \\
\hline & - Dedy & 552 & 204 & Wajah 10 \\
\hline & - Unknown & 343 & 216 & Wajah 11 \\
\hline
\end{tabular}

\subsection{Implementasi Algoritma KNN}

Berikut merupakan analisis sistem pengenalan pola wajah menggunakan media foto dengan metode KNN, data hasil pengujian menggunakan metode KNN dengan $\mathrm{K}$ adalah 3 . Setelah melalui tahap preprocessing dan ekstraksi fitur lalu data training dan data testing akan diklasifikasikan guna dapat diberi label pada data yang diujikan. Berikut merupakan tahapan dana pengelompokkan menggunakan algoritma KNN.

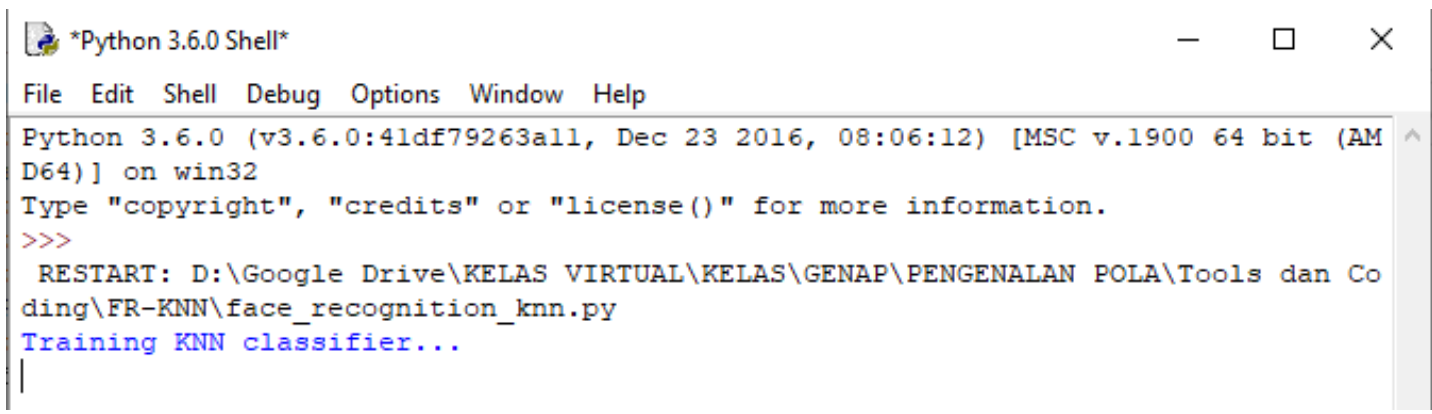

Tabel 3.6 Hasil Uji Citra

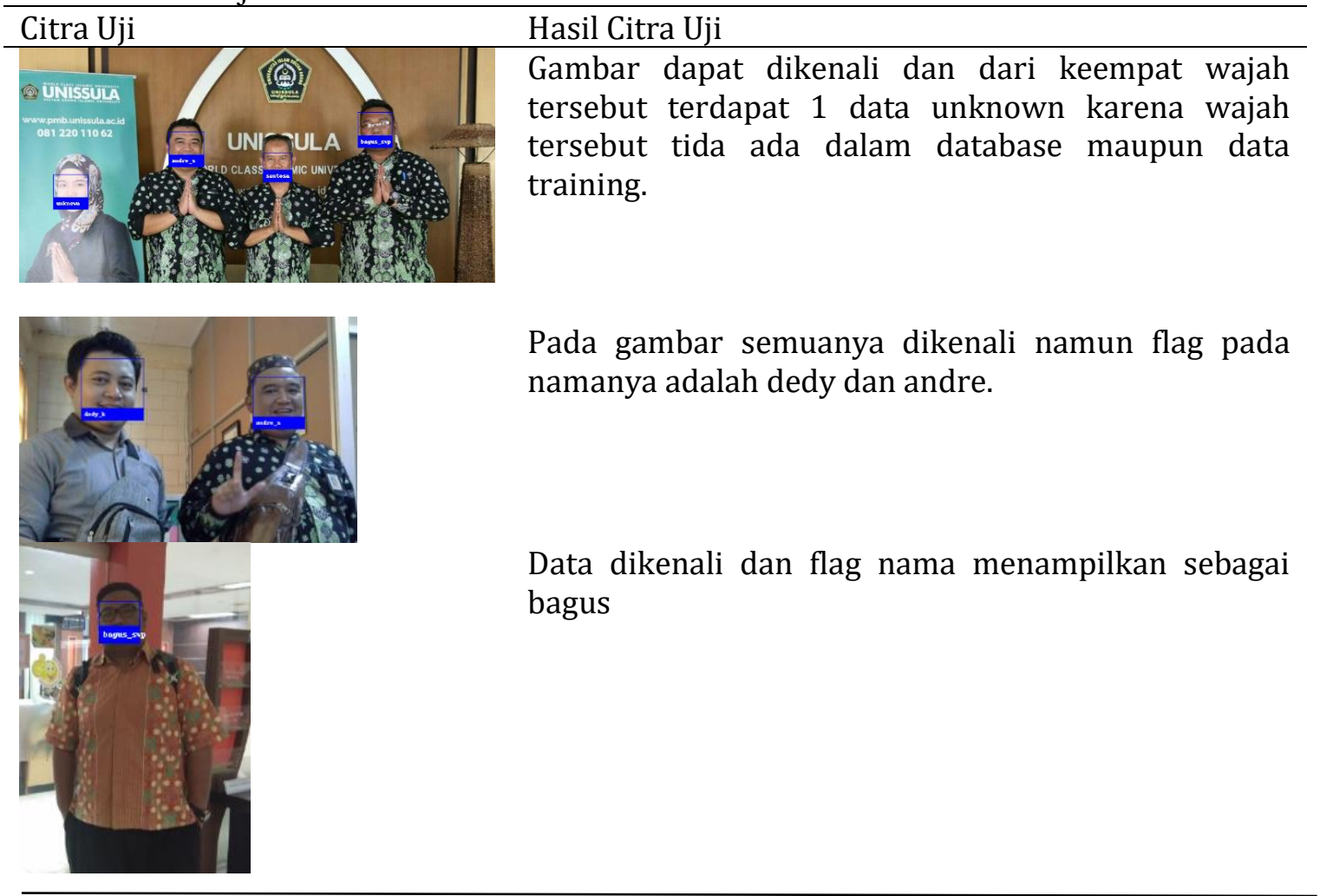

TRANSFORMATIKA Vol. 19, No. 1, July 2021: 17-25 


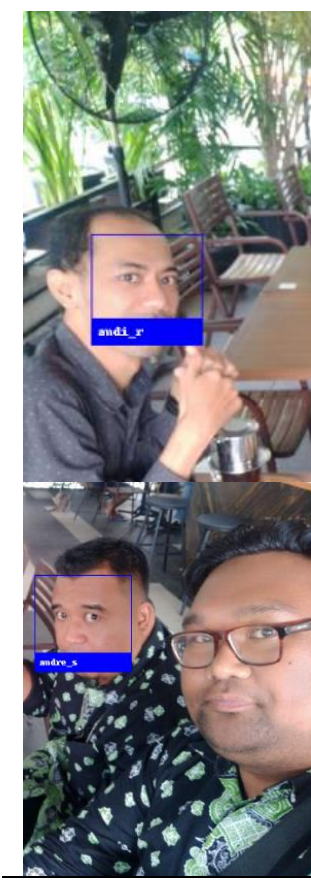

Data dikenali dengan flag nama andi

Terdapat satu gambar tidak terdapat flag nama

\subsection{Perhitungan KNN}

Untuk mendapatkan jarak berdasarkan koordinat T-Zone Area maka jarak koordinat akan dihitung untuk mengetahui jarak terdekat dari data training dan data testing.

Tabel 3.6 Data T-Zone

\begin{tabular}{lllccl}
\hline Citra & Pixel 1 & Pixel 2 & Pixel 3 & Pixel 256 & Label \\
\hline 1 & 0,9659 & 0,033 & 0 & 0 & Unknown \\
2 & 0,9785 & 0,0204 & 0 & 0 & Andre \\
3 & 0,9552 & 0,0437 & 0 & 0 & Santosa \\
4 & 0,9827 & 0,0162 & 0 & 0 & Bagus \\
5 & 0,9573 & 0,0415 & 0 & 0 & Dedy \\
6 & 0,9785 & 0,0204 & 0 & 0 & Andre \\
7 & 0,9827 & 0,0162 & 0 & 0 & Bagus \\
8 & 0.9463 & 0,0134 & 0 & 0 & Andi \\
\hline
\end{tabular}

a. $\quad$ Menghitung $(1,6)$

$$
\begin{aligned}
& =\sqrt{(0,9659-0,9722)^{2}+(0,033-0,9712)^{2}+(0-0)^{2}+(0-0)^{2}} \\
& =\sqrt{0,00001849+0,88021924+0+0} \\
& =\sqrt{0,88023773} \\
& =0,9382098539239502
\end{aligned}
$$

b. Menghitung $(2,6)$

$$
\begin{aligned}
& =\sqrt{(0,9785-0,9722)^{2}+(0,0204-0,9712)^{2}+(0-0)^{2}+(0-0)^{2}} \\
& =\sqrt{0,00006889+0,90402064+0+0} \\
& =\sqrt{0,00013778} \\
& =0,0117379725676967
\end{aligned}
$$

c. Menghitung $(3,6)$

$$
=\sqrt{(0,9552-0,9722)^{2}+(0,0437-0,9712)^{2}+(0-0)^{2}+(0-0)^{2}}
$$




$$
\begin{aligned}
& =\sqrt{0,000225+0,86025625+0+0} \\
& =\sqrt{0,86048125} \\
& =0,9276212858704785
\end{aligned}
$$

d. Menghitung $(4,6)$

$$
\begin{aligned}
& =\sqrt{(0,09827-0,9722)^{2}+(0,0162-0,9712)^{2}+(0-0)^{2}+(0-0)^{2}} \\
& =\sqrt{0,7618322089+0,912025+0+0} \\
& =\sqrt{1,6738572089} \\
& =1,293776336504884
\end{aligned}
$$

e. Menghitung $(5,6)$

$$
\begin{aligned}
& =\sqrt{(0,9573-0,9722)^{2}+(0,0415-0,9712)^{2}+(0-0)^{2}+(0-0)^{2}} \\
& =\sqrt{0,00016641+0,86434209+0+0} \\
& =\sqrt{0,8645085} \\
& =0,9297894923045754
\end{aligned}
$$

Tabel 3.7

\begin{tabular}{lllll}
\hline Citra & Hasil Jarak & Ranking & $\begin{array}{l}3 \text { tetangga } \\
\text { terdekat }\end{array}$ & Label \\
\hline 1 & 0,9382098539239502 & 4 & TIDAK & Andre \\
2 & 0,0117379725676967 & 1 & YA & Bagus \\
3 & 0,9276212858704785 & 2 & YA & Dedy \\
4 & 1,293776336504884 & 5 & TIDAK & Dedy \\
5 & 0,9297894923045754 & 3 & YA & Andi \\
\hline
\end{tabular}

\subsection{Akurasi Sistem}

Hasil uji coba dengan menggunakan nilai $\mathrm{k}=1$ telah dilakukan dapat dilihat pada tabel 3.7 yang mencocokan antara data training dengan data testing.

Tabel 3.8

\begin{tabular}{lllll}
\hline No. & Citra Uji & Data Aktual & Data KNN & Keterangan \\
\hline 1. & Wajah 1 & Unknown & Unknown & Benar \\
2. & Wajah 2 & Andre & Andre & Benar \\
3. & Wajah 3 & Bagus & Bagus & Benar \\
4. & Wajah 4 & Dedy & Dedy & Betul \\
5. & Wajah 5 & Andi & Andi & Benar \\
6. & Wajah 6 & Bagus & No Flag & Error \\
\hline \multicolumn{5}{c}{$\frac{\sum}{\sum \text { correct }} \times 100 \%$} \\
\end{tabular}

Akurasi sistem yang didapat dari 11 citra wajah dengan $\mathrm{K}=1$ didapatkan presentase sebesar $82 \%$

\section{Conclusion}

Algoritma KNN dapat diterapkan kedalam pemrograman python dengan baik dan berdasarkan dari hasil training sampai dengan uji citra pada penelitian ini bahwa algoritma KNN mampu TRANSFORMATIKA Vol. 19, No. 1, July 2021: 17-25 
mengenali objek wajah dengan menentukan tetangga terdekat berdasarkan data training yang ada didalam database, tingkat akurasi pengenalan wajah dengan algoritma KNN adalah sebesar $82 \%$.

\section{References}

[1] B. Warna, K. Dengan, and M. Template, "Penentuan Wilayah Wajah Manusia Pada Citra Berwarna Berdasarkan Warna Kulit Dengan Metode Template Matching," Maj. Ilm. Teknol. Elektro, vol. 5, no. 2, pp. 1-8, 2012, doi: 10.24843/10.24843/MITE.

[2] M. A. Rahman, I. S. Wasista, M. Kom, and L. Belakang, "Sistem Pengenalan Wajah Menggunakan Webcam Untuk Absensi Dengan Metode Template Matching," Elektronika, pp. 1-6, 2015.

[3] C. V. Angkoso, J. T. Informatika, F. Teknik, U. Trunojoyo, E. Fitur, and A. Tekstur, "Pengenalan Jender Berbasis Tekstur Pada Citra Wajah Foto Digital," Konf. Nas. "Inovasi dalam Desain dan Teknol., pp. 119-125, 2011.

[4] I. Santoso, Y. Christyono, and M. Indriani, "Kinerja Pengenalan Citra Tekstur Menggunakan Analisis Tekstur Metode Run Length," Semin. Nas. Apl. Teknol. Inf., vol. 2007, no. Snati, pp. 19-25, 2007.

[5] E. Budianita, J. Jasril, and L. Handayani, "Implementasi Pengolahan Citra dan Klasifikasi K-Nearest Neighbour Untuk Membangun Aplikasi Pembeda Daging Sapi dan Babi Berbasis Web," J. Sains dan Teknol. Ind., vol. 12, no. Vol 12, No 2 (2015): Juni 2015, pp. 242-247, 2015, [Online]. Available: http://ejournal.uinsuska.ac.id/index.php/sitekin/article/view/1005.

[6] M. A. Naufal, "Implementasi Metode Klasifikasi K-Nearest Neighbor (K-NN) untuk Pengenalan Pola Batik Motif Lampung," J. Chem. Inf. Model., vol. 53, no. 9, pp. 16891699, 2017, [Online]. Available: http://digilib.unila.ac.id/28648/3/SKRIPSI TANPA BAB PEMBAHASAN.pdf.

[7] F. Liantoni, "Klasifikasi Daun Dengan Perbaikan Fitur Citra Menggunakan Metode KNearest Neighbor," J. Ultim., vol. 7, no. 2, pp. 98-104, 2016, doi: 10.31937/ti.v7i2.356.

[8] A. Budi, S. Suma'inna, and H. Maulana, "Pengenalan Citra Wajah Sebagai Identifier Menggunakan Metode Principal Component Analysis (PCA)," J. Tek. Inform., vol. 9, no. 2, pp. 166-175, 2018, doi: 10.15408/jti.v9i2.5608.

[9] D. Sutaji and R. Dijaya, "Classification of Milk Fish Quality using Fuzzy K-Nearest Neighbor Method Based on Form Descriptor and Co-Occurrence Matrix," J. Phys. Conf. Ser., vol. 1179, no. 1, 2019, doi: 10.1088/1742-6596/1179/1/012021.

[10] Johan Wahyudi and Ihdahubbi Maulida, "Pengenalan Pola Citra Kain Tradisional Menggunakan Glcm Dan Knn,” J. Teknol. Inf. Univ. Lambung Mangkurat, vol. 4, no. 2, pp. 43-48, 2019, doi: 10.20527/jtiulm.v4i2.37.

[11] R. Armandhani, R. C. Wihandika, and M. A. Rahman, "Klasifikasi Gender berbasis Wajah menggunakan Metode Local Binary Pattern dan Random KNN," J. Pengemb. Teknol. Inf. dan Ilmu Komput., vol. 3, no. 8, pp. 7575-7582, 2019. 